\title{
Control of Suspect/Counterfeit and Defective Items
}

MSC-PRO-301

Revision 2

Effective Date: January 31, 2011

Topic: Quality Assurance 


\section{Control of Suspect/Counterfeit and Defective Items}

\subsection{PURPOSE}

This procedure implements portions of the requirements of MSC-MP-599, Quality Assurance Program Description. It establishes the Mission Support Alliance (MSA) practices for minimizing the introduction of and identifying, documenting, dispositioning, reporting, controlling, and disposing of suspect/counterfeit and defective items (S/CIs).

NOTE: Terms used in this procedure are defined in Appendix A.

\subsection{SCOPE}

This Level 2 Management Control Procedure applies to Mission Support Alliance (MSA) Team employees whose work scope relates to Safety Systems (i.e., Safety Class [SC] or Safety Significant [SS] items), non-safety systems and other applications (i.e., General Service [GS]) where engineering has determined that their use could result in a potential safety hazard.

MSA implements an effective Quality Assurance (QA) Program providing a comprehensive network of controls and verification providing defense-in-depth by preventing the introduction of $\mathrm{S} /$ CIs through the design, procurement, construction, operation, maintenance, and modification of processes. This procedure focuses on those safety systems, and other systems, including critical load paths of lifting equipment, where the introduction of S/CIs would have the greatest potential for creating unsafe conditions as recommended by:

DOE G 414.1-3 (Guide, 11/03/2004, HS) Suspect/Counterfeit Items Guide for Use with 10 CFR 830 Subpart A, Quality Assurance Requirements, and DOE O 414.1B, Quality Assurance.

NOTE: "Defense-in-depth" refers to the multiplicity of design features, controls, and actions taken to ensure public and worker safety.

\subsection{IMPLEMENTATION}

This procedure is effective upon publication.

\subsection{REQUIREMENTS}

\subsection{Identification, Control, and Reporting Requirements}

NOTE: For the table in this section under the requirement "type" column, "V" means verbatim and "I" means interpreted.

\begin{tabular}{|c|l|c|c|}
\hline$\#$ & \multicolumn{1}{|c|}{ Requirement } & $\begin{array}{c}\text { Type } \\
\text { V or I }\end{array}$ & \multicolumn{1}{|c|}{ Source } \\
\hline 1. & $\begin{array}{l}\text { Cognizant management shall develop and implement S/CI } \\
\text { controls as part of QA Programs/Plans and must be } \\
\text { commensurate with the facility/activity hazards and } \\
\text { mission impact. }\end{array}$ & I & $\begin{array}{c}\text { CRD 414.1C, } \\
\text { Sec. 4.a; } \\
\text { MSC-MP-599, }\end{array}$ \\
\hline \hline
\end{tabular}




\section{Control of Suspect/Counterfeit and Defective Items}

\begin{tabular}{|c|c|c|c|}
\hline 2. & $\begin{array}{l}\text { The controls shall include mechanisms for maintaining, } \\
\text { updating, and disseminating current accurate information } \\
\text { on S/CI and associated suppliers. }\end{array}$ & I & $\begin{array}{l}\text { CRD 414.1C, } \\
\text { Sec. 4.a.5 }\end{array}$ \\
\hline 3. & $\begin{array}{l}\text { The management point of contact (POC) responsible for } \\
\text { S/CI activities shall be identified to ensure that the DOE } \\
\text { Office of Environment, Safety and Health has a viable } \\
\text { recipient for S/CI information notices. }\end{array}$ & I & $\begin{array}{l}\text { CRD 414.1C, } \\
\text { Sec. 4.a.6 }\end{array}$ \\
\hline 4. & $\begin{array}{l}\text { Management systems shall include identification, } \\
\text { evaluation, and disposition of S/CIs in safety applications } \\
\text { and other applications that create potential hazards. }\end{array}$ & $\mathrm{I}$ & $\begin{array}{l}\text { CRD 414.1C, } \\
\text { Sec. 4.b.3 }\end{array}$ \\
\hline 5. & $\begin{array}{l}\text { S/CIs regardless of safety class are considered reportable } \\
\text { conditions and shall be reported as an Occurrence Report } \\
\text { (OR) in accordance with U.S. Department of Energy } \\
\text { (DOE) Directive CRD M 231.1-2, Occurrence Reporting } \\
\text { and Processing of Operations Information. }\end{array}$ & $\mathrm{I}$ & $\begin{array}{l}\text { CRD 414.1C, } \\
\text { Sec. 4.b.8 }\end{array}$ \\
\hline 6. & $\begin{array}{l}\text { MSA shall notify the local Office of the Inspector General } \\
\text { (OIG) and the DOE, Richland Operations Office (RL) } \\
\text { within three working days of the date an S/CI is confirmed. }\end{array}$ & I & $\begin{array}{l}\text { CRD 414.1C, } \\
\text { Sec. 4.b.8; } \\
\text { DOE G 414.1-3, } \\
\text { Sec. 6.2.5 }\end{array}$ \\
\hline 7. & $\begin{array}{l}\text { Prior to destroying or disposing of S/CI and their } \\
\text { documents, the Inspector General shall be consulted to } \\
\text { determine whether to retain them for criminal investigation } \\
\text { of litigation. }\end{array}$ & I & $\begin{array}{l}\text { CRD 414.1C, } \\
\text { Sec. 4.b.6 }\end{array}$ \\
\hline 8. & $\begin{array}{l}\text { S/CI controls shall be implemented by identifying technical } \\
\text { and QA requirements in procurement specifications, and } \\
\text { assuring that only items that comply with procurement } \\
\text { specifications are accepted. Inspection of inventory and } \\
\text { storage areas shall be conducted to identify, control and } \\
\text { disposition any S/CIs, as required. }\end{array}$ & I & $\begin{array}{l}\text { CRD 414.1C, } \\
\text { Sec. 4.b.2 }\end{array}$ \\
\hline 9. & $\begin{array}{l}\text { S/CI controls shall include control of the introduction and } \\
\text { use of S/CIs through design, procurement, testing, and } \\
\text { inspection/maintenance, evaluation and disposition. No } \\
\text { S/CI shall be used or introduced intentionally unless found } \\
\text { acceptable through the disposition process. }\end{array}$ & $\mathrm{I}$ & $\begin{array}{l}\text { CRD 414.1C, } \\
\text { Sec. 4.a.1 } \\
\text { Sec. 4.a.4 }\end{array}$ \\
\hline 10. & $\begin{array}{l}\text { S/CIs that are discovered during routine maintenance } \\
\text { and/or inspection of non-safety related applications shall be } \\
\text { reported, evaluated, and dispositioned to prevent their } \\
\text { future use in safety related applications }\end{array}$ & I & $\begin{array}{l}\text { CRD 414.1C, } \\
\text { Sec. 4.b.5 }\end{array}$ \\
\hline
\end{tabular}




\section{Control of Suspect/Counterfeit and Defective Items}

\begin{tabular}{|c|l|c|c|}
\hline 11. & $\begin{array}{l}\text { Engineering shall be involved in the procurement process } \\
\text { for items to be procured that have been determined to } \\
\text { require S/CI controls. Engineering shall be involved in } \\
\text { preparing and reviewing the scope of work/material } \\
\text { requisitions for the procurement and assist in developing } \\
\text { criteria for inspection and testing, and assuring appropriate } \\
\text { testing methods are defined. Engineering shall be involved } \\
\text { when replacing, maintaining, or modifying equipment. }\end{array}$ & $\begin{array}{c}\text { CRD 414.1C, } \\
\text { Sec. 4.b.1 } \\
\text { Sec. 4.b.4; }\end{array}$ \\
\hline 12. & $\begin{array}{l}\text { Independent assessments shall be planned and conducted to } \\
\text { measure the adequacy of work performed in complying } \\
\text { with applicable requirements and determine the } \\
\text { effectiveness of QA Program implementation. }\end{array}$ & I \\
\hline 13. & $\begin{array}{l}\text { Independent assessment schedules shall be developed based } \\
\text { on status, complexity, risk, and importance of the activity } \\
\text { and coordinated with ongoing activities to be assessed. }\end{array}$ & I & $\begin{array}{c}\text { MSC-MP-599, } \\
\text { Section 10.0, } \\
\text { Para. 2.1.2 }\end{array}$ \\
\hline
\end{tabular}

\subsection{Training Requirements}

\begin{tabular}{|c|c|c|c|}
\hline 1. & $\begin{array}{l}\text { Managers of employees involved with S/CI controls, shall } \\
\text { ensure they are trained. The designated audience includes } \\
\text { personnel who function in one or more of the following job } \\
\text { categories and have the potential to encounter or make } \\
\text { decisions regarding S/CI as part of their normal work scope: } \\
\text { - Operations engineering managers and supervisors; } \\
\text { - } \quad \text { Engineers (facility/ project, component, design, } \\
\text { maintenance, new construction, or modifications, } \\
\text { - } \quad \text { Srocurement Design Authorities) and their supervisors; } \\
\text { - Quality Engineers and Inspectors; } \\
\text { - Corrective Maintenance Planners; } \\
\text { - Facility Maintenance Supervisors; } \\
\text { - Crafts (fitters, welders, mechanics, carpenters, } \\
\text { machinists, electricians, truck drivers, storekeepers, tool } \\
\text { - crib attendants, equipment operators, etc.); } \\
\text { - Construction Managers; } \\
\text { - } \quad \text { Occurrence Reporting personnel; } \\
\text { - Purchase Card Holders with the realistic expectation of } \\
\text { ordering potential S/CI as determined and documented } \\
\text { by responsible management. } \\
\text { This training shall include prevention, detection, processing } \\
\text { and disposition of S/CI. }\end{array}$ & I & $\begin{array}{c}\text { CRD 414.1C, } \\
\text { Sec. 4.a.2; } \\
\\
\text { MSC-MP-599, } \\
\text { Sec. 2.0, 2.2.1 and } \\
2.2 .3\end{array}$ \\
\hline
\end{tabular}




\section{Control of Suspect/Counterfeit and Defective Items}

\subsection{Trending Requirements}

\begin{tabular}{|c|l|c|c|}
\hline 1. & $\begin{array}{l}\text { Trend analysis shall be conducted and S/CI information } \\
\text { reviewed for dissemination through Lessons Learned as a } \\
\text { means for improving all S/CI activities. }\end{array}$ & I & $\begin{array}{c}\text { CRD 414.1C, } \\
\text { Sec. 4.b.9; } \\
\text { MSC-MP-599, } \\
\text { Sec. 3.0, 2.5.1 }\end{array}$ \\
\hline
\end{tabular}

\subsection{PROCESS}

\subsection{Identification, Control, Reporting, and Documentation}

\begin{tabular}{|c|c|c|}
\hline Actionee & Step & Action \\
\hline QA Manager & 1. & Appoint an S/CI Subject Matter Expert (S/CI SME). \\
\hline \multirow[t]{3}{*}{ S/CI SME } & 2. & $\begin{array}{l}\text { S/CI SME solicits assignment of S/CI Points of Contact (POCs) from } \\
\text { Responsible Organization Managers. }\end{array}$ \\
\hline & 3. & $\begin{array}{l}\text { Maintain a listing of responsible organization S/CI POCs for MSA- } \\
\text { wide reference. The S/CI POC List shall be reviewed at least annually } \\
\text { to ensure that it remains current. }\end{array}$ \\
\hline & & $\begin{array}{l}\text { NOTE: A listing of current S/CI POCs, training information, suspect } \\
\text { fastener head markings, etc. is maintained by the S/CI SME on the } \\
\text { Hanford Intranet at Mission Support Alliance (MSA)/ } \\
\text { Suspect/Counterfeit Items. }\end{array}$ \\
\hline
\end{tabular}

Assigned S/CI POCs
Personnel acquiring/ procuring items or services

4. Act as S/CI MSA Point of Contact for DOE and outside oversight organizations.

5. Coordinate S/CI activities within the assigned responsible organization.

6. Support S/CI SME relative to S/CI issues and activities.

7. Act as focal point and information resource for responsible organization personnel relative to the MSA S/CI program.

8. Ensure acquisition/procurement of items/services (including rental equipment)/subcontracts include appropriate training requirements, technical specifications, procurement quality clauses documentation requirements, e.g., Certified Material Test Reports (CMTRs), and inspection requirements to prevent the entry of S/CIs on site. 


\section{Control of Suspect/Counterfeit and Defective Items}

Actionee

\begin{tabular}{l}
\multicolumn{1}{c}{ Actionee } \\
\hline \\
Design \\
Authority/QA \\
Representative \\
\\
Buyer/Contract \\
Specialist
\end{tabular}

Design

Authority/QA

Representative

Inspection

Personnel
Step

NOTE: Items identified on the Prohibited Items List shall be procured through the procurement process, and not purchased using the P-Card process (refer to MSC-PRO-335, Use and Control of Purchasing Card, and the MSA P-Card Holders User Manual).

9. As required by MSC-PRO-268, Control of Purchased/Acquired Items and Services, ensure development of inspection and testing criteria, testing methods, QAIPs and/or checklists that include specific characteristics for detection of S/CIs.

10. Procure items as requested and assure that all requirements in the statement of work and/or purchase requisition, including receipt inspection, are flowed down to the subcontractor, as well as the flowdown of appropriate general provisions concerning S/CI to prevent entry onsite.

11. Ensure provisions for the detection, identification, control, reporting, evaluation, and disposition of S/CIs are included in responsible organization work control documents involving safety related applications; or other applications that create safety hazards, as determined by the Design Authority.

12. Verify and document that items being inspected do not exhibit indicators attributed to S/CIs as described in DOE G 414.1-3 Suspect/Counterfeit Items Guide for Use with 10 CFR 830 Subpart A, Quality Assurance Requirements, and DOE O 414.1B, Quality Assurance, as required by the governing work control document.

13. When S/CIs are discovered, ensure completion of the following:

- Initiate a nonconformance report (NCR) in accordance with MSCPRO-298, Nonconforming Items.

- If suspect/counterfeit fasteners are involved, complete a Suspect Fastener Headmark Report (Site Form BC-6000-853) and attach to the NCR.

NOTE: When S/CI are discovered by other individuals than Quality Assurance personnel, they shall immediately notify responsible Quality Assurance personnel who will document the discovery on a NCR in accordance with MSC-PRO-298 and control the item(s)/material(s) pending disposition of the NCR. 


\section{Control of Suspect/Counterfeit and Defective Items}

MSC-PRO-301, Rev. 2

Effective Date: January 31, 2011

Page 6 of 12

\begin{tabular}{lcl}
\multicolumn{1}{c}{ Actionee } & Step & \multicolumn{1}{c}{ Action } \\
\hline QA & 14. & $\begin{array}{l}\text { Notify manager of the responsible organization owning the S/CI } \\
\text { material and transmit NCR for disposition in accordance with MSC- } \\
\text { PRO-298, Nonconforming Items. }\end{array}$ \\
& 15. $\begin{array}{l}\text { Ensure that S/CIs continue to be controlled, subsequent to their } \\
\text { identification, pending formal disposition including application and } \\
\text { removal of status indicator tags. Application and maintenance of status } \\
\text { tags is performed in accordance with MSC-PRO-297, Inspection, Test } \\
\text { and Operating Status. }\end{array}$
\end{tabular}

Design Authority

16. Disposition NCRs in accordance with MSC-PRO-298, Nonconforming Items. When the final disposition is approved immediately notify the personnel responsible to initiate an occurrence report.

Responsible

Organization

Managers

QA

Representatives, or Originators

17. Once an item has been confirmed to be Suspect/Counterfeit through the NCR dispositioning process, initiate an Occurrence Report, for all $\mathrm{S} / \mathrm{CIs}$ identified, in accordance with MSC-PRO-060, Reporting Occurrences and Processing Operations Information.

18. Within two working days of S/CI confirmation via NCR final disposition, provide a copy of the NCR, OR, and other pertinent documents/reports to the S/CI SME.

NOTE: The OIG requires all S/CIs to be reported within three working days of the date of confirmation. Providing the S/CI SME with the information within two working days provides time to process and transmit the information within the three day window.

19. Provide NCRs pertaining to procurement activities to Acquisition Verification Services (AVS).

S/CI SME

20. Within three working days of confirmation, report all S/CI to the OIG and the DOE-RL Contracting Officer via electronic mail to the RL, Safety and Environment Division representative.

Responsible Organization Managers

21. Ensure that rejected S/CI is packaged with a copy of the Nonconformance Report, identified with a "HOLD” tag in accordance with MSC-PRO-297, and transported to Bldg. 2101M for storage pending disposal.

NOTE: On occasion, it is acceptable for the S/CI SME to take custody of S/CI for training or display purposes. On these occasions the S/CI $S M E$ will assure traceability by indicating transfer from the hold location to secure storage of the item(s) in a locked cabinet in his office. 


\section{Control of Suspect/Counterfeit and Defective Items}

MSC-PRO-301, Rev. 2

Effective Date: January 31, 2011

Page 7 of 12

Actionee

$2101 \mathrm{M}$ and

4732A

Warehouse

Personnel

S/CI SME

S/CI POCs

QA Programs, S/CI POCs

Cognizant Managers
Step

Action
22. Upon receipt, place S/CI in controlled storage pending authorization for disposal from the S/CI SME.

23. Ensure OIG authorization is obtained prior to destroying, or disposing of S/CIs.

NOTE: S/CIs that have been contaminated are packaged and disposed of, when permitted, in accordance with governing waste management procedures.

24. Ensure QA schedules and performs surveillance of responsible organization implementation of S/CI controls, within each POC's assigned scope of responsibility, as specified via this procedure, at least once a year. QA shall utilize the lines of inquiry listed in the Standard QA Surveillance Checklist, as applicable to the responsible organization being surveilled, located on the Quality Assurance website. Specific objective evidence reviewed during performance of the surveillance shall be documented in the resulting surveillance report.

NOTE: Additional unscheduled QA responsible organization related surveillances may also be required due to new S/CI discoveries or concerns.

25. Ensure S/CI lines of inquiry are included in assessments of other areas which interface with S/CI processes.

26. Ensure documentation associated with S/CIs is complete and adequate.

27. Ensure all Records are controlled and transmitted in accordance with MSC-PRO-10588, Records Management Processes.

\subsection{Training}

\begin{tabular}{lrl}
\multicolumn{1}{c}{ Actionee } & Step & \multicolumn{1}{c}{ Action } \\
\hline Employee's & 1. & Identify and assign employees, in job categories designated in Section \\
Manager & & $\begin{array}{l}\text { 4.2.1, that have the potential to identify or make decisions regarding } \\
\text { S/CI as part of their normal work scope, to attend appropriate S/CI } \\
\text { training. This training shall include prevention, detection, processing } \\
\text { and disposition of S/CIs. }\end{array}$
\end{tabular}

NOTE: Managers may solicit input from QA personnel to assist in the 


\section{Control of Suspect/Counterfeit and Defective Items}

correct identification of the designated audience and training requirements.

2. Contracted labor resources whose scope of work includes performance of work onsite which falls into one or more of the job categories required to complete S/CI awareness training via Section 4.2.1, shall complete required S/CI training (course \# 170720 or equivalent) to ensure S/CIs do not enter the Hanford Site as a result of their work scope and to ensure they are capable of identifying potential S/CI if they are encountered. It is the responsibility of the assigned BTR/Manager to ensure this training is completed.

3. Ensure successful completion of Course 170720, Suspect Counterfeit Items, or equivalent as determined by MSA Training, by designated personnel.

4. Ensure completion of web-based S/CI refresher training, by designated personnel, within one year of successful completion of Course 170720, and annually thereafter.

\subsection{Trending}

Actionee

Date Statistician

S/CI SME

S/CI POCs and QA

Representatives

\section{Step}

1. Provide S/CI trend reports, which include all Occurrence Reports, to the S/CI SME on a quarterly basis, in accordance with $\underline{\text { MSC-PRO- }}$ 24741, Performance Analysis Process.

2. Review S/CI trending information provided by the Data Statistician of S/CIs for trends in accordance with MSC-PRO-4294, Performance Indicator Process.

3. Process issues, improvement actions, and adverse trends, in accordance with MSC-PRO-052, Corrective Action Management.

4. Review S/CI information for dissemination in accordance with MSCPRO-067, Managing Lessons Learned, and MSC-PRO-4294 Performance Indicator Process.

\subsection{FORMS}

Suspect Fastener Headmark Report Form, BC-6000-853 


\section{Control of Suspect/Counterfeit and Defective Items}

MSC-PRO-301, Rev. 2

Effective Date: January 31, 2011

Page 9 of 12

\subsection{RECORD IDENTIFICATION}

Records Capture Table

\begin{tabular}{|l|c|c|}
\hline \multicolumn{1}{|c|}{ Name of Document } & Submittal Responsibility & Retention Responsibility \\
\hline $\begin{array}{l}\text { Suspect Fastener Headmark } \\
\text { Report }\end{array}$ & Initiating Organization & Information Management \\
\hline
\end{tabular}

\subsection{REFERENCES}

\subsection{Source References}

DOE O 414.1C, Quality Assurance

MSC-MP-599, Quality Assurance Program Description

DOE G 414.1-3 (Guide, 11/03/2004, HS) Suspect/Counterfeit Items Guide for Use with 10 CFR

830 Subpart A, Quality Assurance Requirements, and DOE O 414.1B, Quality Assurance

10 CFR 830.122 Subpart A, Quality Assurance Criteria

CRD M 231.1-2, Supplemented Rev. 7, Occurrence Reporting and Processing of Operations Information

DOE/RL-92-36, Hanford Site Hoisting and Rigging Manual

\subsection{Working References}

MSC-PRO-052, Corrective Action Management

MSC-PRO-060, Reporting Occurrences and Processing Operations Information

MSC-PRO-067, Managing Lessons Learned

MSC-PRO-268, Control of Purchased/Acquired Items and Services

MSC-PRO-297, Inspection, Test and Operating Status

MSC-PRO-298, Nonconforming Items

MSC-PRO-335, Use and Control of Purchasing Card

MSC-PRO-4294, Performance Indicator Process

MSC-PRO-10588 Records Management Processes

MSC-PRO-24741, Performance Analysis Process

MSC-RD-210, Records Management Program

MSA P-Card Holders User Manual 


\section{Control of Suspect/Counterfeit and Defective Items}

\section{APPENDIX A \\ Definitions and Commonly Used Terms}

The following definitions apply specifically to this procedure:

Critical Load Path: A structural component (e.g., a bolt) in a crane, hoist, transporter, or other handling or lifting equipment that bears the load being lifted or moved and whose failure under tensile or shear stress could result in an operational safety problem or an unacceptable risk of injury to workers or the public.

Defective Items (DI): A defective item or material is any item or material that does not meet the commercial standard or procurement requirements as defined by catalogs, proposals, procurements specifications, design specifications, testing requirements, contracts, or the like. It does not include parts or services that fail or are otherwise found to be inadequate because of random failures or errors within the accepted reliability level.

Manufacturers generally notify their customers when defective items are identified through such mechanisms as recall notices. Such notices may be directly sent to customers, or may appear in Federal agency or industry databases.

DI contain items in which the defect appears to be due to an unintentional error in the manufacturing process. Defective items are often recalled by their manufacturers. Archived DI are also available. The link to defective items will contain certain recalls from the U.S. Consumer Product Safety Commission (CPSC) deemed significant and applicable to DOE operations. CPSC is charged with protecting the public from unreasonable risks of serious injury or death from more than 15,000 types of consumer products. You can find information on over 4,000 product recalls using the various searches at:

http://www.cpsc.gov/cpscpub/prerel/prerel.html

Defective Items will be processed in accordance with MSC-PRO-298, Nonconforming Items.

Defense-in-Depth: The multiplicity of design features, controls, and actions taken to ensure public and worker safety.

Fastener: A metallic screw, nut, bolt, or stud having internal or external threads, with a nominal diameter of 6 millimeters or greater, in the case of such items described in metric terms, or $1 / 4$ inch or greater, in the case of such items described in terms of the English system or measurement, or a load-indicating washer, that is through-hardened or represented as meeting a consensus standard that calls for through-hardening, and that is grade identification marked or represented as meeting a consensus standard that requires grade identification marking, except that such term does not include any screw, nut, bolt, stud, or load-indicating washer that is -

- Part of an assembly;

- A part that is ordered for use as a spare, substitute, service, or replacement part, unless that part is in a package containing more than 75 of any such part at the time of sale, or that is a part contained in an assembly kit; 


\section{Control of Suspect/Counterfeit and Defective Items}

- Produced and marked as ASTM A 307 Grade A, or a successor standard thereto;

- Produced in accordance with ASTM F 432, or a successor standard thereto;

- Specifically manufactured for use on an aircraft if the quality and suitability of those fasteners for that use has been approved -

o By the Federal Aviation Administration; or

o By a foreign airworthiness authority as described in part 21.29, 21.500, 21.502, or 21.617 of title 14 of the Code of Federal Regulations;

- Manufactured in accordance with a fastener quality assurance system; or

- Manufactured to a proprietary standard, whether or not such proprietary standard directly or indirectly references a consensus standard or any portion thereof.

Source: Public Law 101-592 (as amended by P.L. 104-113, and P.L. 105-234 and P.L. 10634), Section 3. Definitions, part 6.

Grade Identification: Any symbol appearing on a fastener purporting to indicate that the fastener's base material, strength properties, or performance capabilities conform to a specific standard of a consensus standards organization or government agency.

Graded Classifications: System used to determine minimum requirements for SSC (e.g., design, operation, procurement, and maintenance requirements). The graded classifications in order of precedence are SC, SS, and GS.

High Strength Graded Fastener: Fasteners that are through-hardened or represented as meeting a consensus standard that requires through-hardening, and are grade identification marked or represented as meeting a consensus standard that requires grade identification marking. Examples of high strength graded fasteners include those produced and procured in accordance with the Society of Automotive Engineers Standard J429, Grades 5, 5.2, 8, and 8.2; ASTM Standard A325, Types 1, 2, and 3; ASTM A490, ASTM A354, ASTM A449 (I\&II), and some ASTM F468.

Nonsafety System: A part or item not within the definition of a Safety System.

Safety Class Structures, Systems, or Components (Safety Class SSCs): The structures, systems, or components, including portions of process systems, whose preventive or mitigative function is necessary to limit radioactive hazardous material exposure to the public, as determined from safety analyses. (10 CFR 830.3)

Safety Significant Structures, Systems, or Components (Safety Significant SSCs): The structures, systems, or components that are not designated as safety class structures, systems, or components, but whose preventive or mitigative function is a major contributor to defense in depth and/or worker safety as determined from safety analyses. (10 CFR 830.3) 


\section{Control of Suspect/Counterfeit and Defective Items}

MSC-PRO-301, Rev. 2

Effective Date: January 31, 2011

Page 12 of 12

Safety System: A DOE/NNSA nuclear and nonnuclear facility structure, system, or component whose preventive or mitigative function is a major contributor to defense-in-depth (i.e., prevention of uncontrolled material release) or worker safety as determined from hazard analysis. Also, a DOE structure, system, or component, including, a primary environmental monitor or a portion of a process system, whose failure could adversely affect the environment, safety, or health of the public or workers.

Suspect/Counterfeit Item: An item is suspect when inspection or testing indicates that it may not conform to established government or industry-accepted specifications or national consensus standards or whose documentation, appearance, performance, material, or other characteristics may have been misrepresented by the supplier or manufacturer. A counterfeit item is one that has been copied or substituted without legal right or authority or whose material, performance, or characteristics have been misrepresented by the supplier or manufacturer. Items that do not conform to established requirements are not normally considered S/CIs if nonconformity results from one or more of the following conditions (which must be controlled by site procedures as nonconforming items):

- Defect resulting from inadequate design or production quality control.

- Damage during shipping, handling, or storage.

- Improper installation.

- Deterioration during service.

- Degradation during removal.

- Failure resulting from aging or misapplication.

- Other controllable causes.

Source: DOE O 414.1C, Quality Assurance, Section 7, Definitions, part r; 10 CFR 830.120, Quality Assurance Requirements; and DOE 5700.6C, Quality Assurance 